\author{
D. Yardeni · H. Yardeni · A. G. Coran · E. S. Golladay
}

\title{
Severe esophageal damage due to button battery ingestion: can it be prevented?
}

Accepted: 8 March 2004 / Published online: 22 June 2004

(C) Springer-Verlag 2004

\begin{abstract}
Batteries represent less than 2\% of foreign bodies ingested by children, but in the last 2 decades, the frequency has continuously increased. Most ingestions have an uneventful course, but those that lodge in the esophagus can lead to serious complications and even death. Medline was used to search the English medical literature, combining "button battery" and "esophageal burn" as keywords. Cases were studied for type, size, and source of the batteries; duration and location of the battery impaction in the esophagus; symptoms; damage caused by the battery; and outcome. Nineteen cases of esophageal damage have been reported since 1979.Batteries less than $15 \mathrm{~mm}$ in diameter almost never lodged in the esophagus. Only 3\% of button batteries were larger than $20 \mathrm{~mm}$ but were responsible for the severe esophageal injuries in this series. These data suggest that manufacturers should replace large batteries with smaller ones and thus eliminate most of the complications. When the battery remains in the esophagus, endoscopic examination and removal done urgently will allow assessment of the esophageal damage, and treatment can be tailored accordingly. There is a need for more public education about the dangers of battery ingestion; this information should be included as part of the routine guidelines for childproofing the home.
\end{abstract}

Keywords Button battery $\cdot$ Esophageal burn

D. Yardeni $(\bowtie)$

Pediatric Surgery Department,

Haemek Medical Center, 18101 Afula, Israel

E-mail: danhadar@012.net.il

Tel.: + 972-4-6494324

Fax: +972-4-6521148

D. Yardeni · A. G. Coran · E. S. Golladay

Section of Pediatric Surgery,

C.S. Mott Children's Hospital,

University of Michigan Medical School,

Ann Arbor, MI, USA

H. Yardeni

Maccabi Health Service, North Zone, Israel

\section{Introduction}

Although most cases of button battery ingestion end uneventfully, those batteries that lodge in the esophagus can result in serious complications and even death. Batteries account for less than $2 \%$ of the foreign bodies ingested by children, but over the last 2 decades, the frequency has continuously increased $[1,2,3]$.During a 7 year period from July 1983 through June 1990, the National Button Battery Ingestion Hotline in the United States reported 2,382 battery ingestions [1]. The average annual increase of reported cases during this period was $24 \%$, and the annual incidence of battery ingestion is estimated at a minimum of 2,100 cases per year. In this report, the battery lodged in the esophagus in only 16 children. In eight children, the battery spontaneously passed into the stomach while the child awaited operative intervention. Although batteries that lodged in the esophagus required removal in less than $0.35 \%$ of the cases, severe complications were found only in this group.

Since 1979, the English literature reports 19 cases of severe esophageal damage due to button battery ingestion. In reviewing these published cases, several common features emerge. We present one additional case in which a severe esophageal burn occurred less than $6 \mathrm{~h}$ after ingestion.

\section{Case report}

A 7-year-old white male child, while playing at home, took a battery out of a Gameboy-like device and swallowed it. He denied chewing on it. He then began having chest and upper abdominal pain, and his parents took him to the emergency department of another hospital. A chest radiograph showed an Americanquarter-sized disk battery lodged at the junction of the proximal two-thirds and distal one-third of the esophagus. A repeat film on arrival at our hospital approximately $4.5 \mathrm{~h}$ later showed the foreign body to be in the same location. On initial evaluation, x-ray 


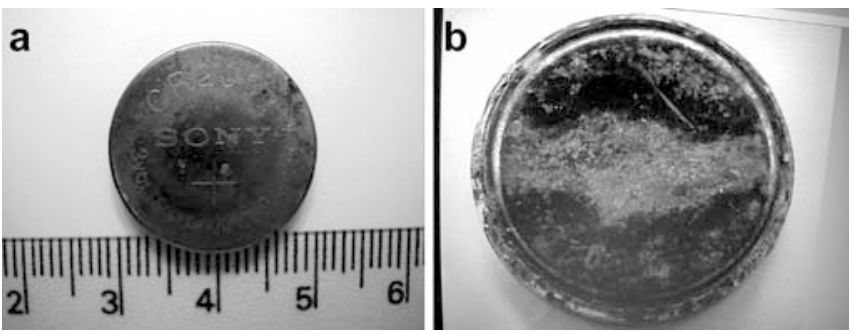

Fig. 1 a A $20 \mathrm{~mm}, 3 \mathrm{~V}$ lithium battery removed from the esophagus of a 7-year-old boy about $6 \mathrm{~h}$ after ingestion. b Note the black debris that had already adhered to the top (anode) side of the battery

showed no mediastinal air or other evidence of perforation. The boy had a normal white count and differential. At this time, however, he was having quite severe but episodic epigastric pain.

Shortly after admission, he underwent flexible endoscopy under general anesthesia. A blue-gray discoloration of desquamated esophageal mucosa and necrotic debris surrounding the battery was found $22-25 \mathrm{~cm}$ from the lips. After the debris was cleaned off, a $20 \mathrm{~mm}, 3 \mathrm{~V}$ lithium battery was found and removed (Fig. 1a). Black debris was adherent to the top (anode) side of the battery (Fig. 1b), and a 3-cm burn, about two-thirds the circumference of the esophagus, with the predominant component being anterior, was found at the site of the battery's lodgment (Fig. 2).

The patient received intravenous ampicillin and clindamycin. After the first clindamycin dose, he developed a rash. It was discontinued and metronidazole begun. He had a central venous line placed and received total parenteral nutrition. He was afebrile throughout the course. The morning of discharge, he had a barium swallow that showed mild narrowing at the area of impaction, but no high-grade stenosis (Fig. 3a). A repeat study in 3 weeks showed no abnormality (Fig. 3b), and a year later he had no swallowing problems or any other complaints.

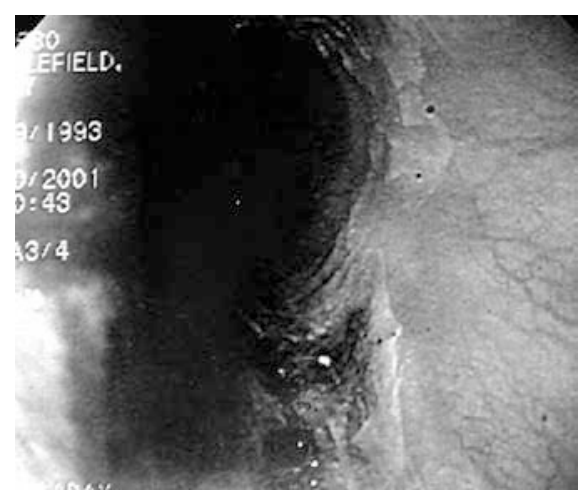

Fig. 2 A 3-cm burn, about two-thirds the circumference of the esophagus, with the predominant component anteriorly positioned at the site of the battery's lodgment
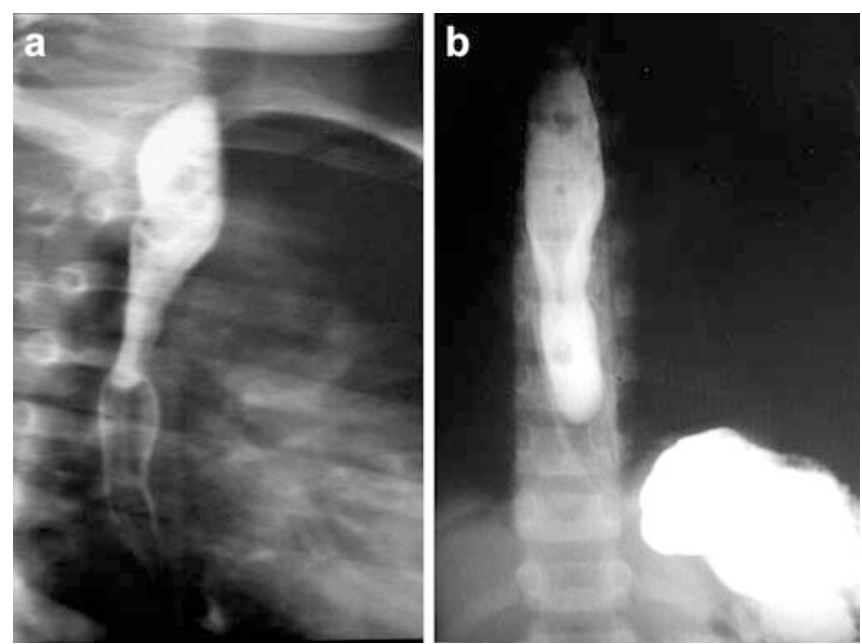

Fig. 3 a Mild narrowing is noted on the esophagogram on the day of discharge, 4 days post-injury. b Four weeks after removal of the battery, an esophagogram shows normal esophageal anatomy

\section{Materials and methods}

Medline was used to search the English medical literature from 1979 to 2002, combining "button battery" and "esophageal burn" as keywords. Nineteen cases of esophageal damage due to button battery ingestion were reported.

Our review carefully excluded duplication of cases. Adding our case, 20 cases were reviewed for this report. These cases were studied with respect to age and gender of the children; type, size, voltage, and source of the batteries; duration and location of the battery impaction in the esophagus; symptoms; clinical signs; damage caused by the battery; and outcome.

\section{Results}

Age

Thirteen of the children were under 2 years, with six being less than 1 year old. This age distribution is similar to that seen with all foreign body ingestions. The relatively high incidence of battery ingestion in the age group of 6-12 years reported by Litovitz et al. [1] was not seen in those who had the battery lodged in the esophagus. The difference probably relates to the decreased likelihood of esophageal impaction in the largerdiameter esophagus of the older child.

\section{Gender}

Gender distribution was equal, as opposed to the male predominance seen with most foreign body ingestions and button battery ingestions that caused no damage [3, 4]. 
Time of diagnosis

In 19 of the 20 children, the time of esophageal exposure was known. The battery was removed in the first $24 \mathrm{~h}$ in six. In another 12 patients, the diagnosis was delayed, in six of them for more than 1 week and in two for longer than a month. In one case, a physician made the correct diagnosis but felt the battery would spontaneously pass, until 2 weeks later when a piece of meat impacted in the child's esophagus [5].

\section{Symptoms}

The most frequent symptom in this series was dysphagia, which was the main complaint in 12 children. Five of the children had fever, four had respiratory distress, and five were irritable. One-third of the patients had no swallowing difficulties and suffered from only minimal and nonspecific symptoms for many days after the ingestion.

Delayed and missed diagnosis

Eight cases were misdiagnosed initially; four children were thought to have respiratory infections $[6,7,8,9]$. One child each was treated for otitis media [10], gastroenteritis [11], and pharyngitis [12].The correct diagnosis was made in the other three cases, but there was a delay in diagnosis of days to weeks [13, 14, 15]. There were several reasons for the delay. In some cases, a clear history of ingestion was not obtained or the symptoms and clinical signs were not sufficiently specific to warrant suspicion. In some other instances, even in the presence of dysphagia and respiratory distress, there was a delay in recognition, suggesting a low level of awareness or suspicion of foreign body on the part of the physicians. These cases of delayed recognition demonstrate the need for an appropriate radiographic evaluation in any case that is compatible with the possibility of esophageal foreign body.

\section{Size of batteries}

A relatively large-sized button battery of more than $15 \mathrm{~mm}$, and usually of $20-23 \mathrm{~mm}$ diameter, caused almost all of the complications [16]. This large-diameter battery, which accounts for only $3 \%$ of the reported ingestions of batteries [1], s much more likely to become lodged in a child's small esophagus.

\section{Type of batteries}

The batteries responsible for the severe burns in this review were of several different chemical types: Six were manganese oxide, three mercury, five lithium, one sodium hydroxide, and one zinc. No specific type was responsible for causing more severe esophageal burns or being quicker in causing damage.

Five types of batteries, based on their chemical composition, are in common use: manganese, silver, mercury, lithium, and zinc [2].Mercuric oxide batteries are the most commonly ingested [17].In Litovitz's analysis, mercuric oxide buttons were the most likely to fragment [1]. Six children showed elevated mercury levels in their blood or urine, and all six patients were symptomatic. Other studies have reported elevated blood mercury levels without symptoms [18] as well as small bowel obstruction in a 2-year-old girl with a mercury blood level of 340 micrograms/1 [19], but no severe toxicity has been reported.

\section{Source of batteries}

Eight batteries came from cameras, two from watches, two from shoe soles, two from toys, and one from a hair drier. The reports from the other five cases did not define the sources.

\section{Location of batteries}

Fifteen batteries impacted in the upper esophagus, which is similar to the location of coin ingestions $[4,20]$. In one-third of the patients, the batteries did not cause dysphagia for more than a week after ingestion.

\section{Esophageal damage and duration of impaction}

There are four mechanisms of injury caused by batteries:

1. Toxic effect due to absorption of substances. Most of the toxic mercuric oxide in batteries changes into nontoxic substances after ingestion, but some batteries contain $5 \mathrm{~g}$ of mercuric oxide, more than a lethal dose. Batteries containing lithium, manganese, and heavy metals other than mercury do not cause toxicity $[18,21]$.

2. Electrical discharge and mucosal burn. Yamashita et al. have shown in animal experiments that it is not necessary for the battery to "leak" alkali to cause mucosal damage [22]. A battery in the esophageal lumen may complete an electrolytic circuit and cause local damage [23, 24, 25].

3. Necrosis due to direct pressure, as can occur with any other foreign body.

4. Caustic injury due to leakage. Votteler et al. showed instantaneous release of the battery's contents when the battery was immersed in saline [13].

Severe esophageal damage may occur after battery impaction in a very short period of time. In one case, a perforation occurred after only $5 \mathrm{~h}$ of exposure [26].This is not surprising; we know from animal models that transmural esophageal necrosis occurs in dogs within 


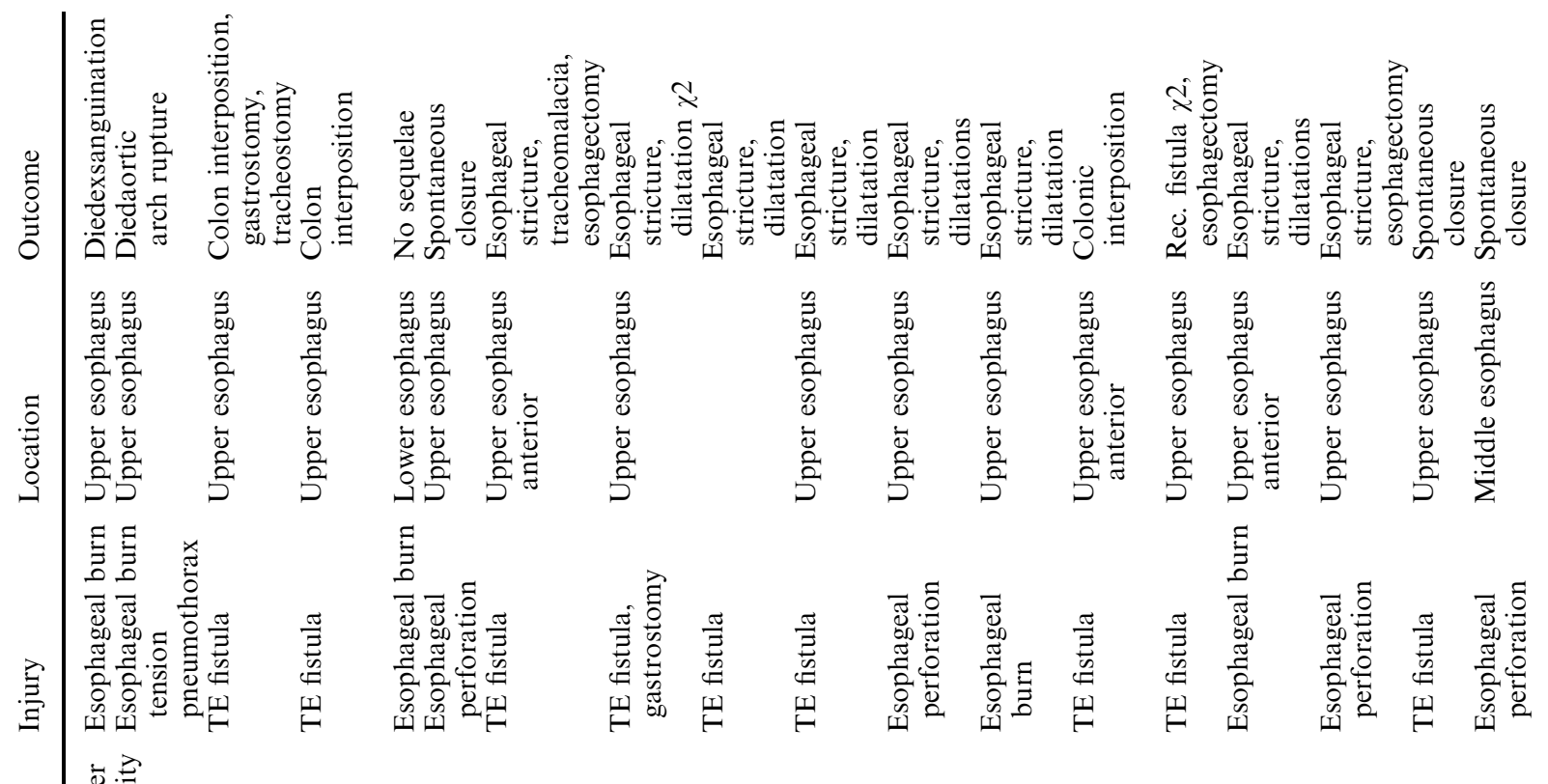

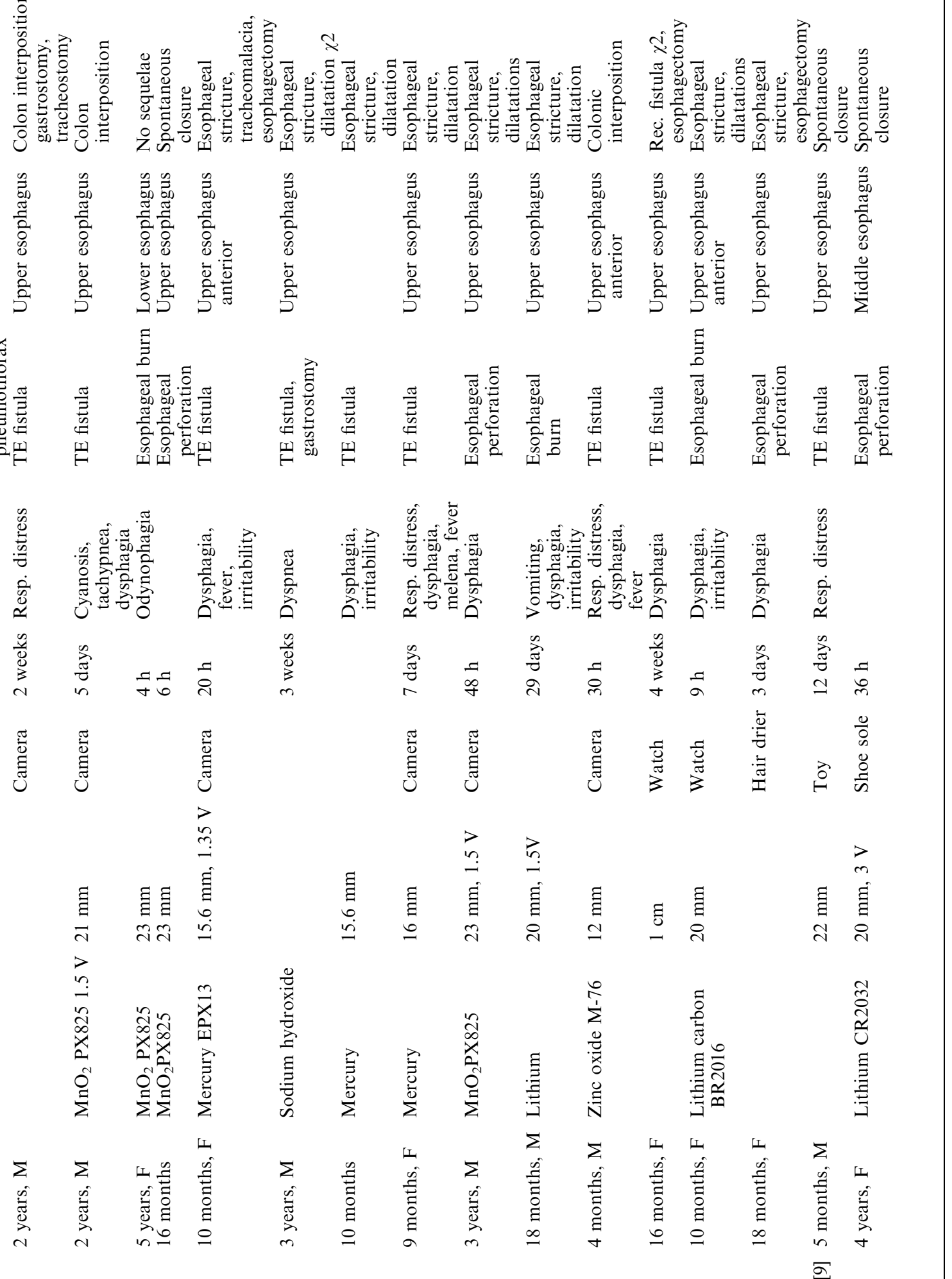

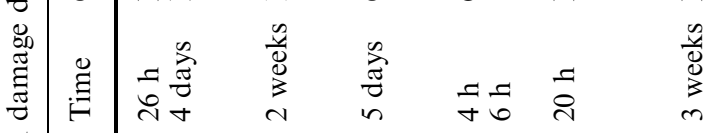

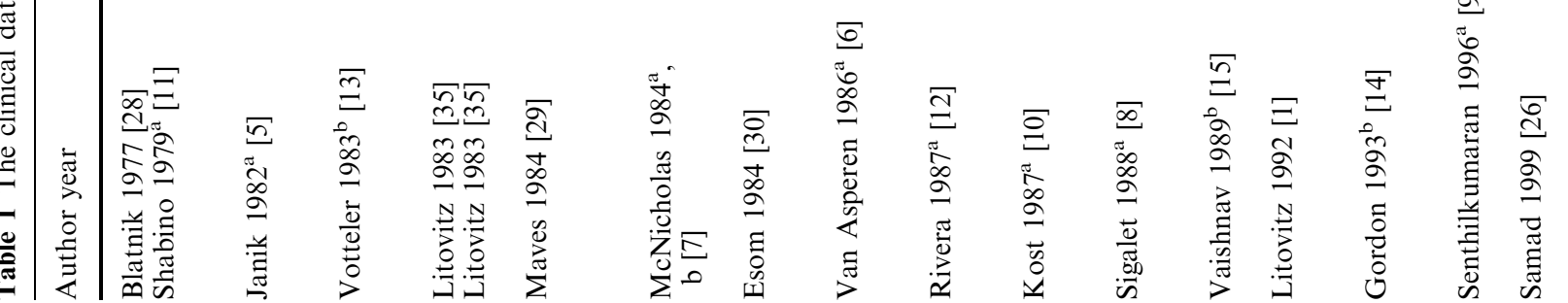

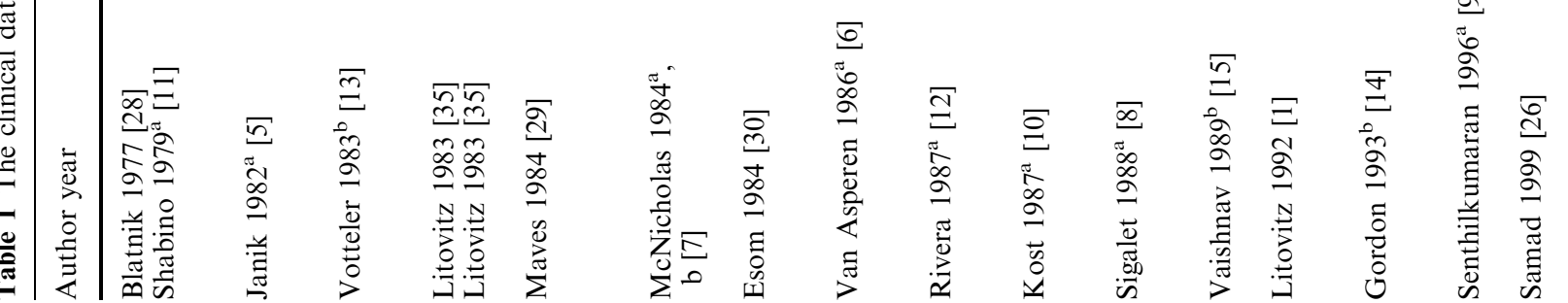

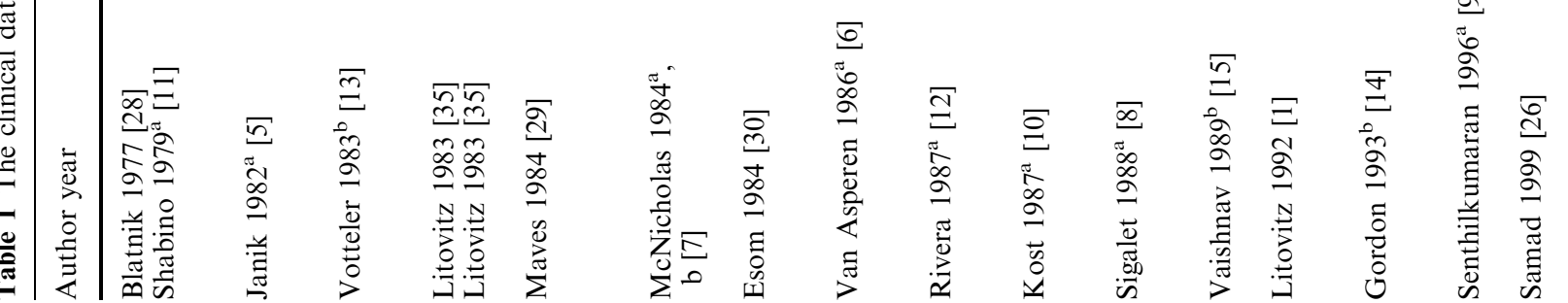

$\bar{a}$ 
$1 \mathrm{~h}[22,27]$ and in cats within $2-4 \mathrm{~h}$ of exposure to the battery [27]. Penetration into the mediastinum was found in seven, and tracheoesophageal fistula was found in another 10 cases.

Removal of esophageal batteries

In this series, 19 children had endoscopic removal of the battery without operative complications.

\section{Outcome}

Death was the outcome in two cases, from vascular injury leading to uncontrollable hemorrhage $[11,28]$. Severe esophageal necrosis necessitated esophageal replacement by colonic interposition in three children [5, $8,13]$. Three children needed partial esophagectomy [14, $15,29]$, and eight needed multiple esophageal dilations for up to 5 years due to esophageal stricture $[1,6,7,10$, $12,14,29,30]$.

\section{Discussion}

The English literature contains more than 2,000 cases of button battery ingestions published during the last 20 years, and the numbers continue to increase. Within this group, more than 20 cases suffered major complications, with almost all of them due to the battery's being lodged in the esophagus. These cases have some interesting common features regarding the causes and mechanism of the injury. We analyzed these in order to define factors that may have been responsible for the severe injuries in an attempt to improve prognosis. Battery ingestion mandates immediate cervical, chest, and abdominal anteroposterior and lateral radiographs. Batteries have a distinctive appearance on radiography, with a "double density" on a PA view and a "step-off" on lateral view [31].

When the battery remains in the esophagus after ingestion, removal is urgently needed. We wish to emphasize again the possibility of perforation after as short a time as $5 \mathrm{~h}$. Emetics rarely are effective. In addition, the emetic could cause a battery in the stomach to reflux back into the esophagus [1]. Although removal by Foley catheter or by a magnet attached to a tube has been reported with good results [32,33], we believe that in cases of esophageal impaction, endoscopic removal and examination should be done so as to assess the damage to the esophagus and tailor treatment accordingly. If there is a significant esophageal burn, the child should not be fed, and antibiotics should be administered until perforation has been ruled out.

A contrast esophagram or esophagoscopy should be done before allowing the child to eat. These studies can be repeated in 3-6 weeks to evaluate for the presence of a stricture. In the case of esophageal perforation and 
tracheoesophageal fistula, the treatment is thoracotomy and closure of the perforation or fistula. However, in this series, out of 17 cases of perforation or fistula, five underwent successful nonoperative treatment, one of them after esophageal impaction for 12 days (Table 1). We therefore believe that nonoperative treatment should be considered if the patient's condition allows.

Although rare cases of elevated blood and urine mercury levels $[18,34]$ and one case of Meckel's diverticulum perforation [24] due to batteries that traversed the esophagus have been reported, most of the severe complications were due to impaction of a large battery in the esophagus. Batteries less than $16 \mathrm{~mm}$ in diameter almost never lodged in the esophagus. Only 3\% of button batteries were greater than $20 \mathrm{~mm}$ [1], and these were the ones responsible for almost all of the severe esophageal injuries in this series. Are the larger batteries really necessary? Two smaller batteries with a diameter of less than $16 \mathrm{~mm}$ can replace one large battery while being much safer. These data suggest that manufacturers should replace large button batteries with smaller ones. This approach would eliminate almost all of the major complications seen. The manufacturers should provide a warning label on products in which large batteries must be used.

There is a need for public education about the danger of button battery ingestions. Primary care physicians should educate the parents about this hazard as part of the routine guidelines for childproofing the home.

\section{References}

1. Litovitz T, Schmitz B.F (1992) Ingestion of cylindrical and button batteries: an analysis of 2382 cases. Pediatrics 89:747757

2. Thompson N, Lowe-Posford F, Mant TGK, Volans GN (1990) Button battery ingestion: a review. Acute Poisoning Rev 9:157182

3. Sheikh A (1993) Button battery ingestions in children. Pediatr Emerg Care 9:224-229

4. Cheng W, Tam PKH (1999) Foreign-body ingestion in children: experience with 1265 cases. J Pediatr Surg 34:1472-1476

5. Janik JS, Burrington JD, Wayne ER, Foley LC (1982) Alkaline battery ingestion. Colo Med 79:404-405

6. Van Asperen PP, Seeto I, Cass DT (1986) Acquired tracheooesophageal fistula after ingestion of a mercury button-battery. Med J Aust 145:412-415

7. McNicholas K, Stark J (1984) Unusual case of benign tracheooesophageal fistula. Thorax 39:311-312

8. Sigalet D, Lees G (1988) Tracheoesophageal injury secondary to disc battery ingestion. J Pediatr Surg 23:996-998

9. Senthilkumaran G, Crankson S, Yousef M (1996) Spontaneous closure of acquired tracheo-oesophageal fistula. J Larygnol Otol 110:685-687
10. Kost KM, Shapiro RS (1987) Button battery ingestion: a case report and review of the literature. J Otolaryngol 16:252-257

11. Shabino CL, Feinberg AN (1979) Esophageal perforation secondary to alkaline battery ingestion. JACEP 8:360-363

12. Rivera EA, Maves MD (1987) Effects of neutralizing agents on esophageal burns caused by disc batteries. Ann Otol Rhinol Laryngol 96:362-366

13. Votteler TP, Nash JC, Rutledge JC (1983) The hazard of ingested alkaline disk batteries in children. JAMA 249:2504-2505

14. Gordon AC, Gough MH (1993) Oesophageal perforation after button battery ingestion. Ann R Coll Surg Engl 75:362-364

15. Vaishnav A, Spitz L (1989) Alkaline battery-induced tracheooesophageal fistula. Br. J Surg 76:1045

16. Litovitz TL (1985) Battery ingestions: product accessibility and clinical course. Pediatrics 75:469-476

17. Millar AJW, Rode H, Cywes S (1985) Button-battery ingestions - a hazard of modern living. S Afr Med J 68:868-871

18. Bass DH, Millar AJW (1992) Mercury absorption following button battery ingestion. J Pediatr Surg 27:1541-1542

19. Mant TG, Lewis JL, Mattoo TK, Rigden SP, Volans GN, House IM, Wakefield AJ, Cole RS (1987) Mercury poisoning after disc-battery ingestion. Hum Toxicol 6:179-181

20. Crysdale WS, Sendi KS, Yoo J (1991) Esophageal foreign bodies in children. 15-year review of 484 cases. Ann Otol Rhinol Laryngol 100:320-324

21. Temple DM, McNeese MC (1983) Hazards of battery ingestion. Pediatrics 71:100-103

22. Yamashita M, Saito S, Koyama K, Hattori H, Ogata T (1987) Esophageal electrochemical burn by button-type alkaline batteries in dogs. Vet Hum Toxicol 29:226-230

23. Nandi P, Ong GB (1978) Foreign body in the oesophagus: review of 2394 cases. Br J Surg 65:5-9

24. Willis GA, Ho WC (1982) Perforation of Meckel's diverticulum by an alkaline hearing aid battery. Can Med Assoc J 126:497498

25. Yee KF, Schild JA, Holinger PH (1975) Extraluminal foreign bodies (coins) in the food and air passages. Ann Otol Rhinol Laryngol 84:619-623

26. Samad L, Ali M, Ramzi H (1999) Button battery ingestion: hazards of esophageal impaction. J Pediatr Surg 34:1527-1531

27. Tanaka J, Yamashita M (1998) Esophageal electrochemical burns due to button type lithium batteries in dogs. Vet Hum Toxicol 40:193-196

28. Blantik DS, Toohill RJ, Lehman RH (1977) Fatal complication from an alkaline battery foreign body in the esophagus. Ann Otolaryngol 86:611-615

29. Maves MD, Carithers JS, Birck HG (1984) Esophageal burns secondary to disc battery ingestion. Ann Otol Rhinol Laryngol 93:364-369

30. Easom JM (1982) Risks from swallowing small alkaline batteries. Pediatr Alert 7:21-22

31. Kuhns DW, Dire JD (1989) Button battery ingestions. Ann Emerg Med 18:293-300

32. McDermott VGM, Taylor T, Wyatt JP, MacKenzie S, Hendry GMA (1995) Orogastric magnet removal of ingested disc batteries. J Pediatr Surg 30:29-32

33. Ito Y, Ihara N, Sohma S(1985) Magnetic removal of alkaline batteries from the stomach. J Pediatr Surg 3:250-251

34. Kulig K, Rumack CM, Rumack BH, Duffy JP (1983) Disk battery ingestion. JAMA 249:2502-2503

35. Litovitz TL (1983) Button battery ingestions: a review of 56 cases. JAMA 249:2495-2500 